\title{
Influence of temperature, humidity, and light on the growth and sporulation of Aschersonia aleyrodis
}

\author{
D. N. Bhosale ${ }^{1}$, Y. V. Ingle ${ }^{2 *}$, D. H. Paithankar ${ }^{3}$ and N. S. Satpute ${ }^{4}$ \\ ${ }^{1}$ Department of Plant Pathology, Dr. PDKV, Akola-444104 Maharashtra, India \\ ${ }^{2 \& 3}$ AICRP on Fruits, Dr. PDKV, Akola 444104 Maharashtra, India \\ ${ }^{4}$ Department of Entomology, Dr. PDKV, Akola 444104 Maharashtra, India \\ *Corresponding author Email:yog_ingle@rediffmail.com \\ (Submitted on March 20, 2020; Accepted on June 8, 2020)
}

\begin{abstract}
The effects of temperature, relative humidity (RH) and light on the growth and sporulation of Aschersonia aleyrodis Webber isolated from the fungus infected nymphs of citrus black fly, Aleurocanthus woglumi, were studied in the laboratory. Maximum colony diameter and spore count was achieved at $25^{\circ} \mathrm{C}$ followed by $30^{\circ} \mathrm{C}$. The relative humidity when kept at $100 \%$ and $85 \%$ gave significantly higher colony growth and spore count. On an average, continuous light condition was preferred which recorded best average growth and sporulation followed by alternate cycle of $12 \mathrm{hr}$ light and $12 \mathrm{hr}$ dark. Quantitative assessments of growth and conidial production over 10 to 15 days under constant conditions showed that growth and sporulation was optimized at temperatures between $20^{\circ} \mathrm{C}$ and $30^{\circ} \mathrm{C}, \mathrm{RH}>80 \%$ and continuous light exposure.
\end{abstract}

Keywords: Aschersonia aleyrodis, temperature, humidity, light and sporulation

\section{INTRODUCTION}

The fungus Aschersonia aleyrodis Webber (PhylumAscomycota; Sub Phylum-Pezizomycotina; ClassSordariomycetes; Sub Class-Hypocreomycetidae; OrderHypocreales; Family-Clavicipitaceae) was first used for controlling whiteflies in citrus groves in Florida in the early 1900s. A combination of predators, parasitoids with $A$. aleyrodis has been in use for managing the citrus whiteflies for decades (Berger, 1921).

Biological control based on the use of entomogenous fungi is not simply dependent upon interaction between the host and the pathogen, but also on the environment to which they are exposed. Range of factors, including, temperature, relative humidity $(\mathrm{RH})$, light, air, nutrient availability and host physiological status influences fungal pathogenicity (Padmini and Padmaja, 2010). Of the diverse factors, temperature, humidity and light are reported to be the foremost essential environmental factors affecting the survival and effectiveness of entomogenous fungi for their use as biocontrol agents (Bugeme et al., 2008).

Stimulating effect of temperature, relative humidity and light on the growth of mycelium and sporulation is well known in case of some of the entomogenous genera including Nomuraea, Beauveria, Metarhizium, and Paecilomyces (Alves et al., 1984; Sharma et al., 1998; Gopalkrishnan and Mohan, 2002; Miętkiewski et al., 1994). However, little information is available on the influence of environmental factors on entomopathogenic fungus Aschersonia aleyrodis. The purpose of the present study was to find out the range of environmental factors which influence the growth and sporulation of this fungus.

\section{MATERIALS AND METHODS}

Isolation and Morphological Identification: The present study was conducted at the Department of Plant Pathology and AICRP on Fruits, Dr. Panjabrao Deshmukh Krishi Vidyapeeth, Akola. The black fly nymph that appeared (Fig. 1) to be infected was collected from Pala village of Morshi Tahsil of Amravati district in the month of August 2019. The fungus infected insect samples were brought to the laboratory and pathogen was isolated on PDA medium following the methodology given by Homrahud et al., (2016). Stromata (Fig 2 a) from the body surface of the collected black fly were scrapped and sterilized using $\mathrm{NaOCl}(0.1 \%)$ solution for 5 minutes followed by rinsing with distilled water several times. Crushed small portion of the infected part of black fly nymph was transferred to culture plate containing PDA medium which was subsequently incubated at $25 \pm 2^{\circ} \mathrm{C}$ for making observation on the growth and development of the colonizing fungus. Mycelial bits of the growing fungus colony were aseptically transferred to fresh PDA plates as well as PDA slants so as to obtain a pure culture. The identification of the fungus was done based on morphology, colony characters, pycnidia, stromata and conidia. The published literature was used to make comparisons and subsequent identification (Samson et al., 1988; Prasad et al., (2004) and Liu et al., 2006).

The morphological characteristics of the isolated fungus were observed using 40X magnification of Zesis Primo Image analyzer microscope. Conidial measurements were done using 'Biovis' software. A. aleyrodis grown on Potato

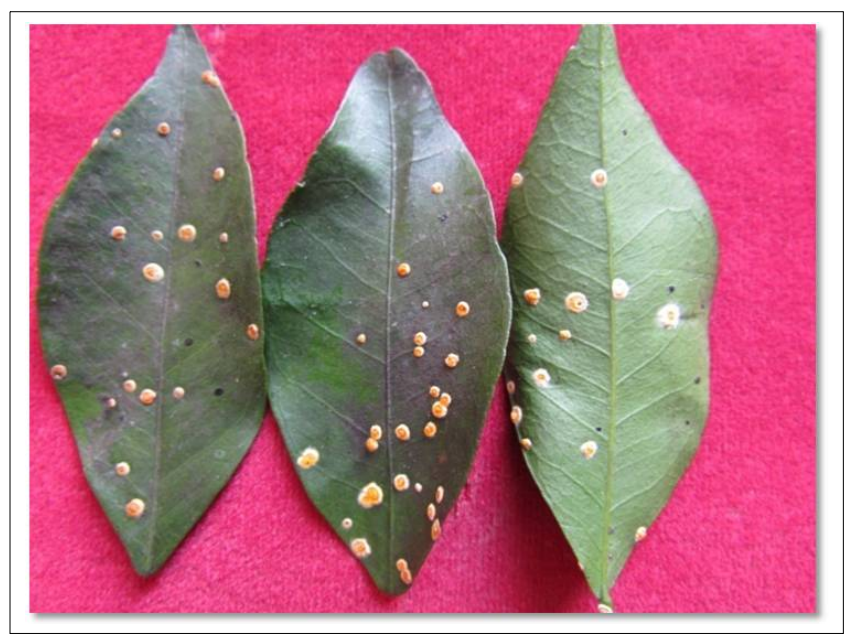

Fig.1: Natural mycosis of black fly nymph on Citrus leaf surface 
dextrose agar media for 10 days and its cultural characters with respect to growth, colony morphology, colony colour, mycelial characters, sporulation, conidia formation, conidial morphology and their size were recorded.

Effect of temperature on growth and sporulation of $A$. aleyrodis isolate: Effect of temperature regimes on mycelial growth and sporulation of $A$. aleyrodis was determined using PDA medium. A $6 \mathrm{~mm}$ disc (contains $0.5 \mathrm{mg}$ of mycelial load) of young sporulating culture of $A$. aleyrodis cut with the help of sterilized cork borer placed at the centre on the agar surface was incubated at $15^{\circ} \mathrm{C}, 20^{\circ} \mathrm{C}, 25^{\circ} \mathrm{C}, 30^{\circ} \mathrm{C}, 35^{\circ} \mathrm{C}$ and $40^{\circ} \mathrm{C}$ in the BOD incubator. Four replications of each temperature were maintained. Following inoculation, radial growth of the mycelium was measured after 10 days using two cardinal diameters drawn at the bottom of each plate and recorded. Conidia were harvested from mycelial discs into $10 \mathrm{~mL}$ triton water in a universal bottle, which was vortexed for $3 \mathrm{~min}$ so as to obtain a homogenous solution. The conidial density was measured from this solution under a light microscope (40X) using a Neubauer hemocytometer.

Effect of relative humidity (RH): Effect of different levels of relative humidity was assessed by using desiccators of equal size containing different concentrations of sulphuric acid + water as per the method suggested by Solomon (1951). The experiment was conducted in five replications and inoculated Petri plates were kept in desiccators' maintaining the levels of humidity at $80,85,90,95$ and 100 per cent. The lid was fixed with grease in order to make the desiccators air tight maintaining definite percentage of relative humidity. The experiment was run at room temperature $\left(22-25 \pm 10^{\circ} \mathrm{C}\right)$. The colony diameter was recorded after ten days interval while sporulation was recorded after fifteen days interval.
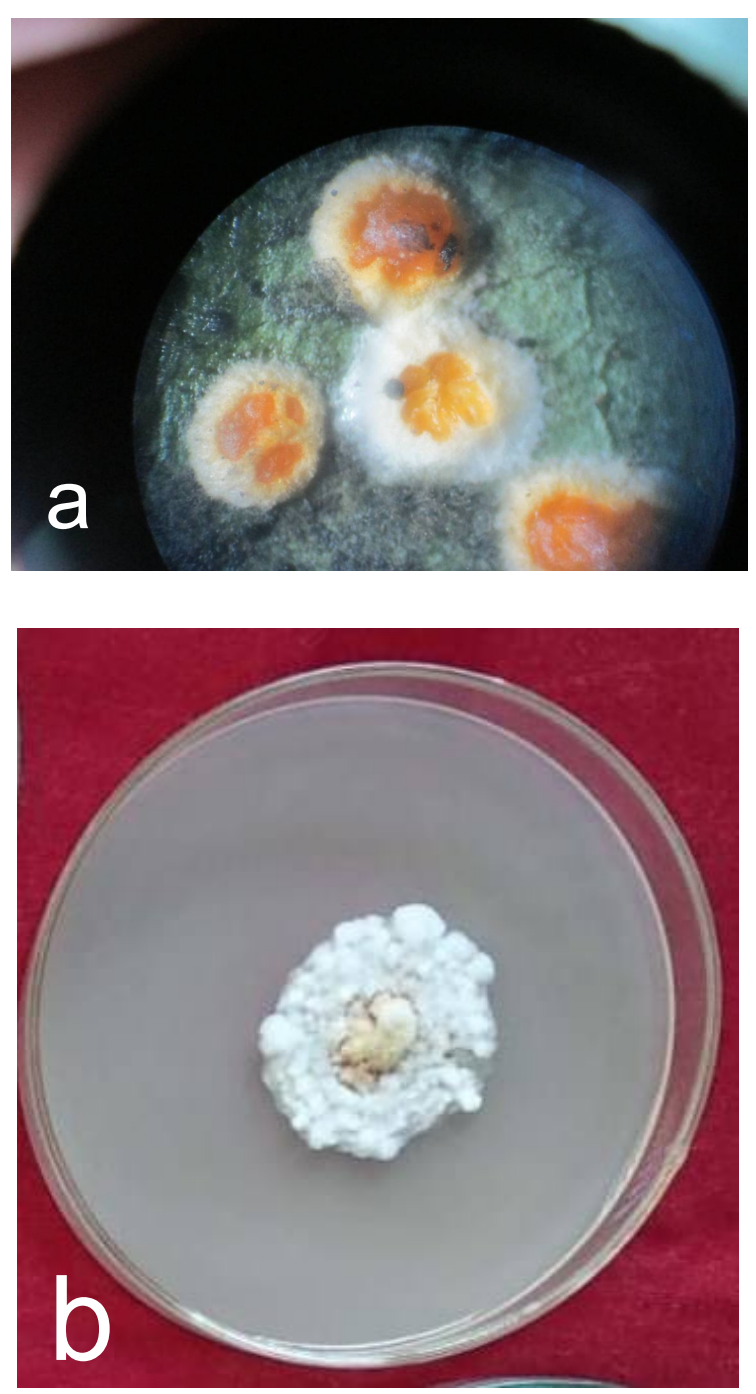
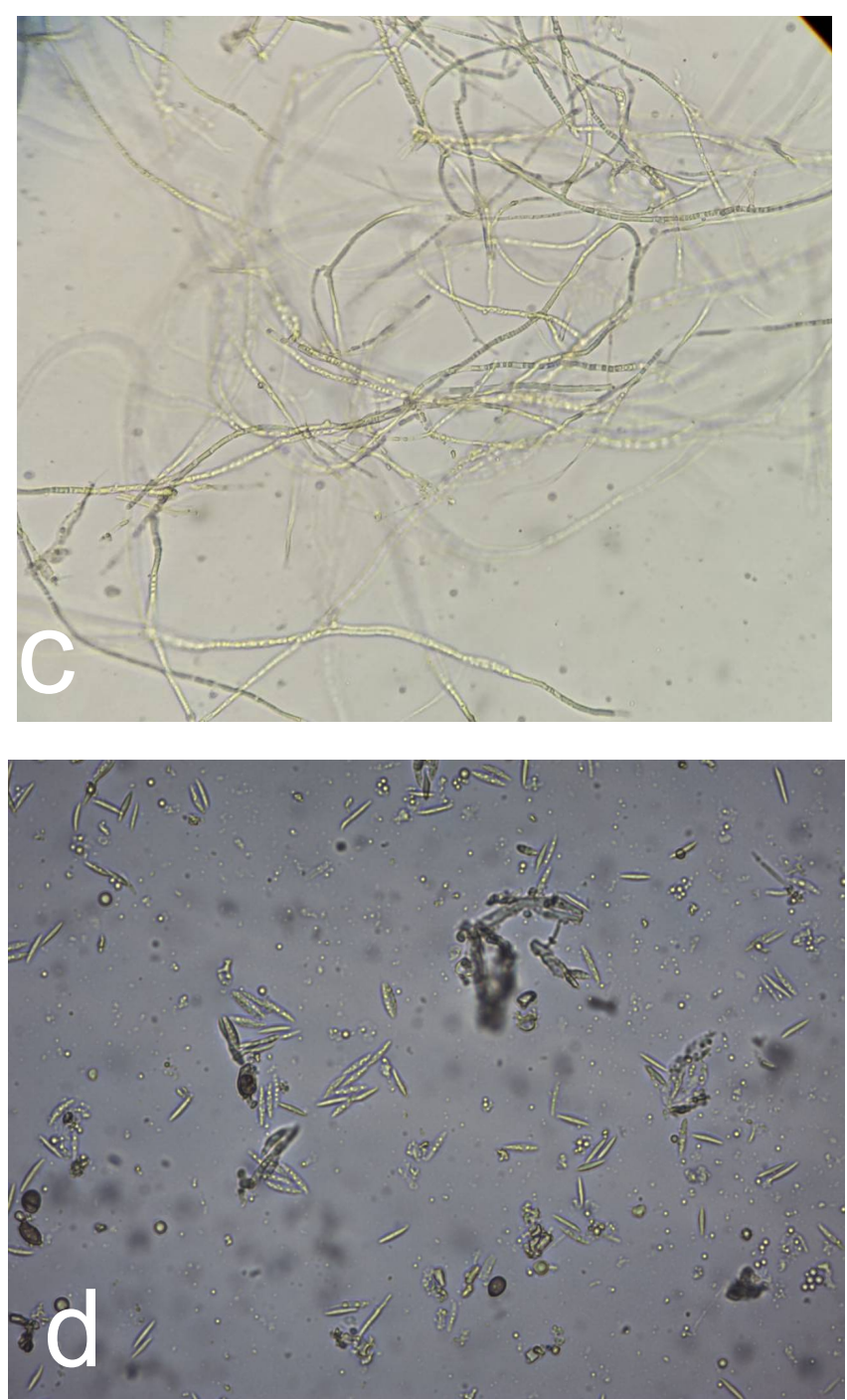

Figs. 2 (a-d) a: Stromata covering nymphs of citrus black fly; b: Colony of A. aleyrodis on PDA medium; c: Mycelium of A. aleyrodis; d: Microscopic view of fusoid conidia of $A$. aleyrodis ( $40 \mathrm{X}$ magnification) 
Effect of light: For ascertaining the effect of light, the inoculated Petri plates in six replications were exposed to (A) continuous light provided by $40 \mathrm{~W}$ white fluorescent tubes arranged $41 \mathrm{~cm}$ above Petri plates, (B) alternate cycle of $12 \mathrm{hr}$ light and $12 \mathrm{hr}$ darkness and (C) complete darkness provided by wrapping black paper from inner and outer side of bell jar. Radial growth of colonies was measured after 10 days and sporulation count was recorded on $15^{\text {th }}$ day.

Statistical analysis: The data collected from the experiments were subjected to analysis of variance for different treatments. Fisher's protected critical difference (CD) test was used to indicate the difference between the treatments at the probability level of $\mathrm{p}<0.01$ following the procedure described by Gomez and Gomez (1984).

\section{RESULTS}

Morphology and colony characteristics: During the present investigations the young nymphs of black fly with natural mycosis due to infection by the fungus which formed stroma on the dorsal side of the body of insect nymph were examined. To look at, the stroma was flattened pulvinate, and the conidiomata produced reddish orange conidial masses. The coloration of the infected portion of the dead black fly nymphs mainly on the ventral side of citrus leaf varied from white to pale yellow and finally orange. The Stromata (Fig. 2a) exhibited a shape similar to a fried egg with the conidial mass on the top giving yellowish orange to deep orange appearance. Portion of $A$. aleyrodis when cultured on PDA medium produced many small mycelial extensions which afterward became tightly packed and formed a hard and compressed colony on the culture medium.

As for colony characters are concerned, the colony was white to light orange or even yellow, effuse, fluffy, and convex having spherical surface with smooth edge. The colony which was observed growing relatively slowly $(40 \mathrm{~mm}$ in 7 days) primarily composed of aggregates of short mycelia that were woven together to form 'stroma'(Fig. 2b). Stromata (1.5-5 $\mathrm{mm}$ in diameter, $0.3-1.0 \mathrm{~mm}$ in height) appeared white to yellowish white with circular to variable shape. Abundant confluent white or light yellow conidial masses were present with creamy yellow to orange conidial surface. Mycelia hyphae were smooth, septate, branched, 3-5 $\mu \mathrm{m}$ wide (Fig. 2c). Yellowish to light yellowish conidial droplets prominently formed near the top and middle of the stroma. Under the microscope, a small ostiole was found on the stroma which represented the exit point of the conidia. Pycnidia embedded in stroma appeared, ovoid to flattened, globose to even circular, 120-340 x 140-300 $\mu \mathrm{m}$. Conidiophores arising monoematously and laterally from thick walled hyphae with whorls of 2-5 conidiogenous cells. Conidia hyaline, fusoid, occasionally slightly curved, apiculate with acute ends, aseptate; smooth measuring 10-12 x 1.5-2.5 $\mu \mathrm{m}$ in size, (Fig. 2 d).

Effect of temperature on growth and sporulation of $\boldsymbol{A}$. aleyrodis: The optimum temperature for growth and sporulation of the fungus was evaluated at $25^{\circ} \mathrm{C}$ (Table 1) which supported the maximum colony diameter and spore count $\left(8.0 \mathrm{~cm}\right.$ and $2.04 \times 10^{6}$ spore $/ \mathrm{mL}$, respectively). The
Table 1: Effect of temperature on growth and sporulation of A. aleyrodis

\begin{tabular}{|c|c|c|c|}
\hline $\begin{array}{l}\text { Sr. } \\
\text { No. }\end{array}$ & $\begin{array}{l}\text { Tempe- } \\
\text { rature }{ }^{\circ} \mathrm{C}\end{array}$ & $\begin{array}{c}\text { Growth (cm)* } \\
\text { 10 DAI }\end{array}$ & $\begin{array}{c}\text { Spore count } 15 \\
\text { DAI } \\
\left(\times 10^{6} \text { spore } / \mathrm{ml}\right) \\
\end{array}$ \\
\hline 1 & 15 & 2.6 & 1.17 \\
\hline 2 & 20 & 4.5 & 1.43 \\
\hline 3 & 25 & 8.0 & 2.04 \\
\hline 4 & 30 & 7.3 & 1.45 \\
\hline 5 & 35 & 3.2 & 1.29 \\
\hline \multirow[t]{3}{*}{6} & 40 & 1.4 & 0.0 \\
\hline & $\mathrm{SE}(\mathrm{m}) \pm$ & 0.06 & 0.012 \\
\hline & $\mathrm{CD}(\mathrm{P}=0.01)$ & 0.26 & 0.056 \\
\hline
\end{tabular}

next best temperature for growth and sporulation was found to be $30^{\circ} \mathrm{C}\left(7.3 \mathrm{~cm}\right.$ and $1.45 \times 10^{6}$ spore $/ \mathrm{mL}$, respectively $)$ followed by $20^{\circ} \mathrm{C}\left(4.5 \mathrm{~cm}\right.$ growth and spore count $1.43 \times 10^{6}$ spore/mL, respectively). There was relatively less growth and sporulation at $15^{\circ} \mathrm{C}$ and $35^{\circ} \mathrm{C}\left(2.6 \mathrm{~cm}\right.$ and $1.17 \times 10^{6}$ spore $/ \mathrm{mL}$ and $3.2 \mathrm{~cm} 1.29 \times 10^{6}$ spore $/ \mathrm{mL}$, respectively). At $40^{\circ} \mathrm{C}$ temperature there was hardly any growth (colony diameter $1.4 \mathrm{~cm}$ ) and no sporulation at all.

Effect of different humidity levels on radial growth and sporulation of $\boldsymbol{A}$. aleyrodis: The test fungus gave appreciable growth at all humidity levels (Table 2). At 100\% and 85\% relative humidity levels significantly higher colony growth and spore count was achieved $\left(9.0\right.$ and $8.9 \mathrm{~cm} ; 2.14 \times 10^{6}$ and $2.09 \times 10^{6}$ spore $/ \mathrm{mL}$, respectively). Similarly at $90 \%$ and $95 \%$ relative humidity levels also equally significant colony diameter was there $(8.6 \mathrm{~cm})$ and sporulation $\left(2.0 \times 10^{6}\right.$ spore $/ \mathrm{mL}$. and $2.02 \times 10^{6} \mathrm{spore} / \mathrm{mL}$, respectively).

Table 2: Effect of Relative humidity on growth and sporulation of A. aleyrodis

\begin{tabular}{|c|c|c|c|}
\hline $\begin{array}{l}\text { Sr. } \\
\text { No. }\end{array}$ & RH (\%) & $\begin{array}{l}\text { Growth } \\
(\mathrm{cm}) * 10 \\
\text { DAI }\end{array}$ & $\begin{array}{c}\text { Spore count } 15 \\
\text { DAI } \\
\left(\times 10^{6} \mathrm{spore} / \mathrm{ml}\right)\end{array}$ \\
\hline 1 & 80 & 8.4 & 1.92 \\
\hline 2 & 85 & 8.9 & 2.09 \\
\hline 3 & 90 & 8.6 & 2.00 \\
\hline 4 & 95 & 8.6 & 2.02 \\
\hline \multirow[t]{3}{*}{5} & 100 & 9.0 & 2.14 \\
\hline & $\mathrm{SE}(\mathrm{m}) \pm$ & 0.03 & 0.01 \\
\hline & $\mathrm{CD}(\mathrm{P}=0.01)$ & 0.14 & 0.04 \\
\hline
\end{tabular}

Effect of light conditions on growth and sporulation of A. aleyrodis: Effect of light conditions on the radial mycelial diameter and spore count was observed after 10 and 15 days of incubation, respectively. On an average exposure to continuous light conditions resulted in an average colony growth of $9.0 \mathrm{~cm}$ and sporulation of $1.61 \times$ $10^{6}$ spore $/ \mathrm{mL}$ (Table 3). Next best growth was observed when alternate regime of $12 \mathrm{hr}$ light and $12 \mathrm{hr}$ dark was given $\left(\left(7.3 \mathrm{~cm}\right.\right.$ radial mycelial growth with $1.46 \times 10^{6}$ spore $/ \mathrm{mL})$. Exposure to continuous darkness resulted in less growth as compared to when continuous light and alternate cycle of day and light were given $(5.2 \mathrm{~cm}$ and 1.19 $\times 10^{6}$ spores/ $\mathrm{mL}$ ). On an overall basis exposure to continuous light conditions favoured optimum growth and sporulation of $A$. aleyrodis. 
Table 3: Effect of light conditions on growth and sporulation of Aschersoniaaleyrodis

\begin{tabular}{|c|l|c|c|}
\hline $\begin{array}{c}\text { Sr. } \\
\text { No. }\end{array}$ & \multicolumn{1}{|c|}{ Treatment } & $\begin{array}{c}\text { Mean colony } \\
(\mathbf{c m}) * \mathbf{1 0} \text { DAI }\end{array}$ & $\begin{array}{c}\text { Spore count15 } \\
\text { DAI } \\
(\times \mathbf{1 0} \mathbf{s p o r e} / \mathbf{m I})\end{array}$ \\
\hline 1 & Continuous light & 9.0 & 1.61 \\
\hline 2 & $\begin{array}{l}\text { Alternate cycle of } 12 \\
\text { hr light and 12 } \mathrm{hr} \\
\text { darkness }\end{array}$ & 7.3 & 1.46 \\
\hline 3 & Continuous darkness & 5.2 & 1.19 \\
\hline & SE(m) \pm & 0.04 & 0.01 \\
\hline & CD $(\mathrm{P}=0.01)$ & 0.16 & 0.02 \\
\hline$*$ Average of six replications & DAI days after inoculation \\
\hline
\end{tabular}

\section{DISCUSSION}

Entomopathogenic fungus $A$. aleyrodis can be a potent candidate for use as bio-control agent in view of its ability to cause notable epizootic disease in whiteflies (Aleyrodidae) and scale insects (Coccidae) in the tropical and subtropical regions (Evans and Hywel Jones, 1990). In India the natural occurrence of $A$. aleyrodis was recorded by Prasad et al. (2004) in forest of Western Ghat in Goa State on the Homopteran insects. Debnath (2016) in North Eastern region reported its infection on scale insect in citrus orchards. So far no systematic studies have been conducted on the mycological aspects and the environmental factors favouring the growth of this species from Vidarbha region of Maharashtra.

The morphological features of the associated fungus were in conformity with the taxonomic details provided in the standard literature on the basis of which it was identified as $A$. aleyrodis (Samson et al., 1988; Liu et al., 2006; Homrahud et al.2016).

Temperature is one of the crucial abiotic factors affecting development and sporulation of entomogenous fungi. During the present investigations temperature ranging between $25^{\circ} \mathrm{C}$ to $30^{\circ} \mathrm{C}$ was found to be favourable for the vegetative growth and sporulation of $A$. aleyrodis (Fig. 3). Similar observations have been documented by Lima et al. (2017) and Homrahud et al. (2016) who reported $25^{\circ} \mathrm{C}$ temperature as the optimum for in vitro growth and sporulation of $A$. aleyrodis. As has

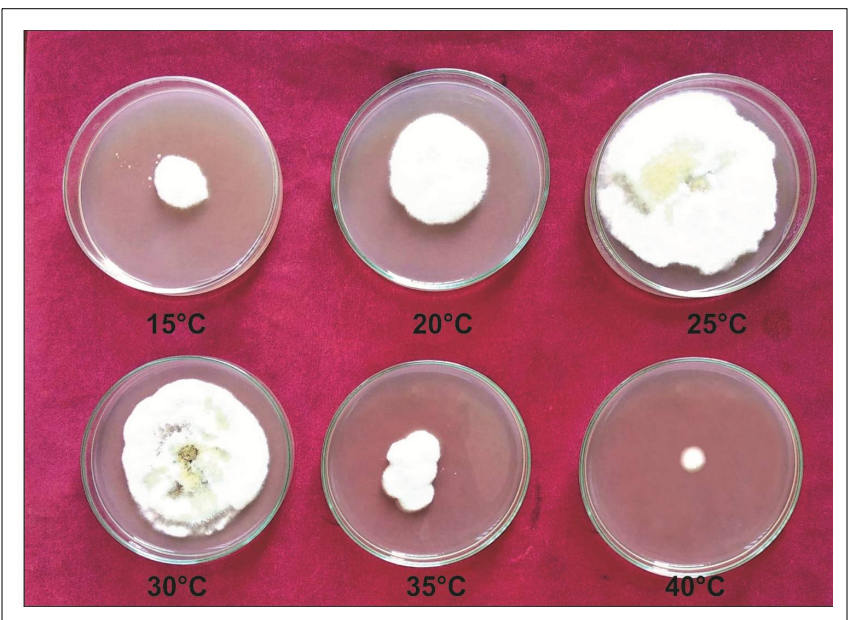

Fig. 3: Effect of temperature on growth and sporulation of $A$. aleyrodis been observed presently, most entomopathogenic fungi are reported to show maximum germination within the temperature range of $20^{\circ} \mathrm{C}$ to $30^{\circ} \mathrm{C}$ (Roberts and Campbell, 1977). Similarly Fransen (1987) reported over $90 \%$ of the spore germination in case of $A$. aleyrodis when grown on water agar in the temperature range of $15^{\circ} \mathrm{C}$ to $28^{\circ} \mathrm{C}$. Mycelia growth and conidial germination of this fungus ranged from $15{ }^{\circ} \mathrm{C}$ to $35^{\circ} \mathrm{C}$ temperature, with $20^{\circ} \mathrm{C}$ to $30^{\circ} \mathrm{C}$ being the optimum. These studies clearly indicate the ability of this entomopathogenic fungus to acclimatize fairly over a wide range of temperature provided other environmental conditions are also favourable.

It is a well known fact that epizootics of mycopathogen are facilitated by number of environmental factors and among them humidity play a significant role in its growth and development. In the current study, there was statistically significant difference observed among the humidity levels (Fig. 4). Relative humidity ranging between $90 \%$ and $95 \%$ was found to be most favourable for the growth and sporulation of this fungus. There are several reports in

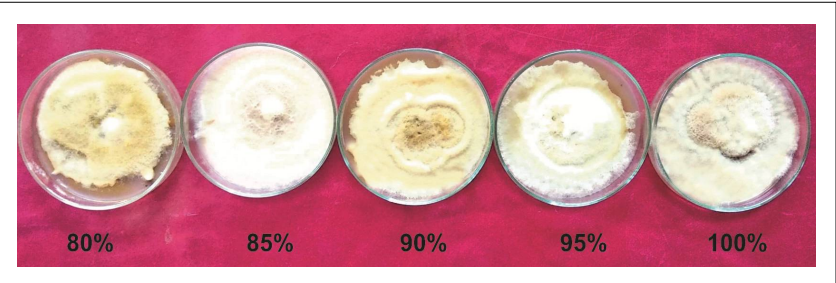

Fig. 4: Effect of RH on growth and sporulation of $A$. aleyrodis

literature showing the increased fungal efficacy, growth and development under high humid conditions (Fransen, 1987; Bugeme et al., 2008; Padmini, and Padmaja, 2010; Homrahud et al., 2016). The present findings are in conformity with the result of Meekes (2000), and Solovei and Koltsov (1983) who reported that high humidity of more than $80 \%$ is most essential for the development of Aschersonia spp. Fransen (1987) also reported that $A$. aleyrodis was able to grow and sporulate at $93.9 \% \mathrm{RH}$ resulting in $88 \%$ germination of spores after incubation for $168 \mathrm{hr}$. In line with the present findings, Vimla Devi and Prasad (2003) also reported that high humidity $(>90 \%)$ is most crucial for development of Nomuraea rielyi, while $75 \% \mathrm{RH}$ restrict the mycelial growth and sporulation. It is apparent from the above observations that availability of high humidity is an obligatory requirement for fungal development, as fungi require a baseline of humid conditions to complete their growth and spore production.

During the present investigations, statistically significant difference was observed in growth and sporulation of the fungus when exposed to light and darkness. Presently it was observed that complete light condition favoured the production of optimum growth and sporulation of test fungus. On the contrary, Sun et al. (2012) reported that light had no remarkable effect on the growth of the Aschersonia aleyrodis, but exposure to 12 hour alternating light is reported to be quite favourable for the spore production. Alves et al. (1984) tested 12 combinations of temperature and photoperiod for the development and sporulation of Metarhizium anisopliae and 


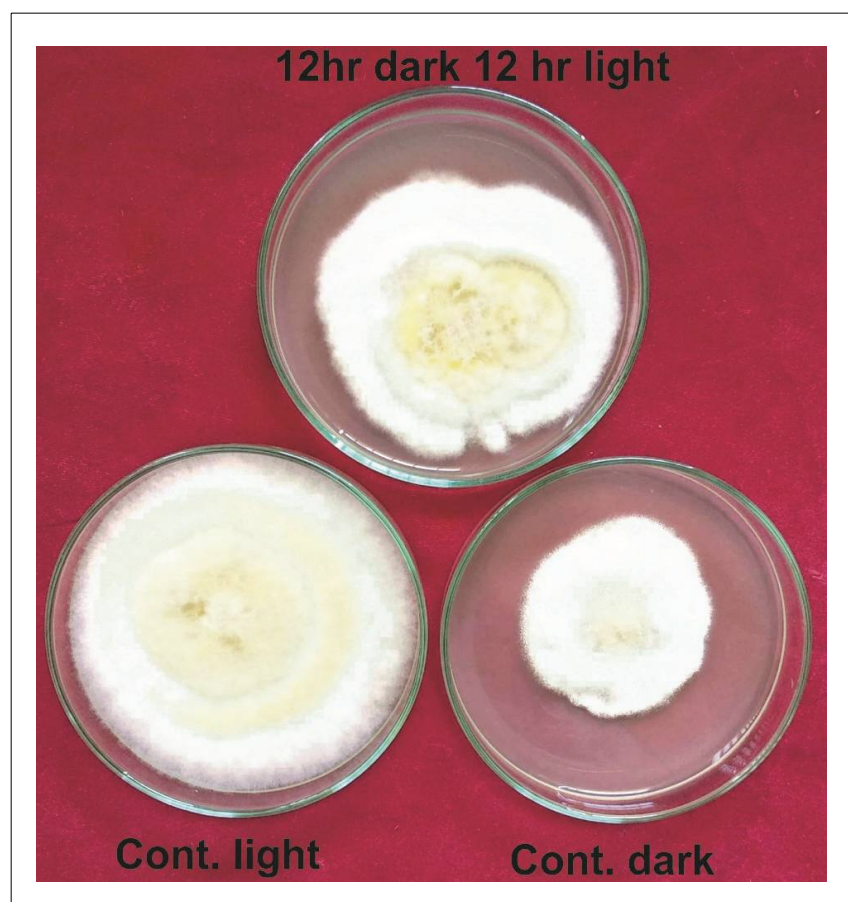

Fig. 5: Effect of different levels of light on growth and sporulation of A. aleyrodis

reported a photoperiod of 16 hours among four varied light regimes to be most suitable for growth and sporulation of $M$. anisopliae. While working with Nomurea rileyi Glare (1987) reported that in vitro sporulation of $N$. rileyi is severely inhibited by complete darkness and light is reported to be essential to produce conidia on the diseased cadavers of Heliothis spp. This observation is exactly what we have observed while working with Aschersonia aleyrodis using different light and dark regimes. In the present study, the change of mycelial pattern was quite evident on the exposure of light in comparison to when grown under complete darkness. Also the colony was a bit creamy white with circular rings under continuous light exposure (Fig. 5) whereas in complete darkness the colony appeared whitish without any concentric ring. This variation clearly denotes that light plays a significant role in the growth and development of $A$. aleyrodis.

\section{CONCLUSION}

Ecological factors affect the mycelial growth and sporulation of Aschersonia aleyrodis in a different way. Optimum temperature of $25^{\circ} \mathrm{C}$ and exposure to more than $85 \%$ relative humidity and continuous light favours maximum growth and sporulation of this entomopathogenic fungus. This in vitro data can form baseline information for in vivo application of A. aleyrodis as a bio-control agent.

\section{ACKNOWLEDGEMENTS}

All sort of assistance rendered by ICAR-AICRP on Fruits scheme for the above study is gratefully acknowledged.

\section{REFERENCES}

Alves, S. B., Risco, S. H. and Almeida, L. C. 1984. Influence of photoperiod and temperature on the development and sporulation of Metarhizium anisopliae (Metsch.) Sorok. Journal of Applied Entomology 97 (1-5): 127-129.

Berger, E. W. 1921. Natural enemies of scale insects and whiteflies in Florida. Florida. Quart. Bull. Fla. Stn. Plant Board 5: 141.

Bugeme, D. M., Maniania, N. K., Knapp, M. and Boga, H.I. 2008. Effect of temperature on virulence of Beauveria bassiana and Metarhizium anisopliae isolates to Tetranychus evansi. Exp. Appl. Acarol. 46 (1-4):275-285.

Debnath, S. 2016. Studies on entomopathogenic fungus Aschersonia aleyrodis infectious to scale insect pest, Saisettia formicarii of tea, Camellia sinensis (L.) Kuntze in Assam. Indian Journal of Fundamental and Applied Life Sciences 6 (3):14-24.

Evans, H. C. and Hywel Jones, N. L. 1990. Aspects of the genera Hypocrella and Aschersonia as pathogens of coccids and whiteflies. In: Proceedings of the 5th International Colloquium of Invertebrate Pathology and Microbial Control. Society for Invertebrate Pathology, Adelaide, SA, Australia, pp. 111-115.

Fransen, J. J. 1987. Aschersonia aleyrodis as a microbial control agent of green house whitefly. $\mathrm{Ph}$. D. Thesis Wageningen Agricultural University, Wageningen Netherland 1-167.

Gomez, K. A. and Gomez, A. A. 1984. Statistical Procedures for Agricultural Research, $2^{\text {nd }}$ edn. John Wiley and Sons, New York, NY, USA.

Gopalkrishnan, C. and Mohan, K. S. 2002. Field efficacy of entomopathogenic fungus Nomuraea rileyi (Farlow) Samson against Spodoptera litura Fabricius in beet root. In : Biopesticides and Pest Management Vol. 2 (Eds.: Koul Opender, Dhaliwal, G.S., Marwaha, S.S. and J.K. Arora) Campus Books International, New Delhi pp 254-259.

Glare, T. R. 1987. Effect of host species and light conditions on production of conidia by an isolate of $N$. rileyi. $J$. Invertebr. Pathol. 50:67-69.

Homrahud, D., Uraichuen, S. and Attathom, T. 2016. Cultivation of Aschersonia placenta Berkeley and Broom and its efficacy for controlling Parlatoria ziziphi. Agriculture and Natural Resources 50: 179185.

Lima, B. M. G. V., Almida, J. E. M., Moreira, J. O. T., Santos, L.C. and Bittencourt, M. A. L. 2017. Entomopathogenic fungi associated with citrus blackfly (Alerocanthhus wogulmi) in southern Bahia. Arg. Inst. Biot. 84 (1): 1-3.

Liu, Miao, Chaverri, P. and Hodge, K. T. 2006. A taxonomic revision of the insect bio-control fungus Aschersonia aleyrodis, its allies with white stroma and their Hypocrella sexual states. Mycological 
Research 10: 537-554.

Meekes, E. T. M., J. F. Joanne and C. L. Joop, 2002. Pathogenicity of Aschersonia spp. against whiteflies Bemisia argentifolii and Trialeurodes vaporariorum. J. Invertebr. Pathol. 81: 1111.

Miętkiewski, R., Tkaczuk, C., Zurek, M. and Vander Geest, L. P. S. 1994. Temperature requirements of four entomopathogenic fungi. Acta Mycol. 29 (1): 109-120.

Padmini, P. C. P. and Padmaja, V. 2010. Impact of different relative humidities on in vitro growth and sporulation of entomopathogenic fungal isolates of Beauveria species. Int. J. Pharm. Biol. Sci. Arch. 1: 355-359.

Prasad, K., Ashwani Kumar, T. S. and Bhat, D. J. 2004. New records of Aschersonia from forest of Western Ghtas, India. J. Mycol. Pl. Pathol. 34(1):7-14.

Roberts, D. W. and Campbell, A. S. 1977. Stability of entomopathogenic fungi. Misc. Publ. Entomol. Soc. Amer. 10: 19-76.

Samson, R. A., Evan, H. C., and Latge, J. P. 1988. Atlas of Entomopathogenic Fungi. Springer-Verlag,
Amsterdam, The Netherlands.

Sharma, S., Gupta, R. B. L. and Yadav, C. P. S. 1998. Effect of temperature on growth sporulation and bioactivity of entomofungal pathogens against white grub. Indian J. Entomology 60 (1): 1-7.

Solomon, M. E. 1951. Control of humidity with potassium hydroxide, sulphuric acid or other solution. Bull. Ento. Res. 42: 543-554.

Solovei, E. F. and Koltsov, P. D. 1976. The action of entomogenous fungi of the genus Aschersonia on the whitefly. Mikol. Fitopatol.10(5): 425-429.

Sun, C., Liao, Q. and Peng, L.2012. Identification and biological characteristics of Aschersonia aleyrodis Webber on Dialeurodes citri Ashmead. Guangdong Agricultural Sciences. (http://en.cnki.com.cn/ Article en/CJFDTotal-GDNY201203031.htm).

Vimla Devi, P. S. and Prasad, Y. G. 2003. Influence of different temperatures on the efficacy of Nomuraea rileyi (F) Samson against Spodoptera litura Fabricus. J. Oilseeds Res. 20 (1): 162-164. 